\title{
Vasodilators in the treatment of acute heart failure: what we know, what we don't
}

\author{
Marco Metra · John R. Teerlink · Adriaan A. Voors • \\ G. Michael Felker · Olga Milo-Cotter · \\ Beth Weatherley · Howard Dittrich · Gad Cotter
}

Published online: 19 December 2008

(C) The Author(s) 2008. This article is published with open access at Springerlink.com

\begin{abstract}
Although we have recently witnessed substantial progress in management and outcome of patients with chronic heart failure, acute heart failure (AHF) management and outcome have not changed over almost a generation. Vasodilators are one of the cornerstones of AHF management; however, to a large extent, none of those currently used has been examined by large, placebocontrolled, non-hemodynamic monitored, prospective randomized studies powered to assess the effects on outcomes, in addition to symptoms. In this article, we will discuss the role of vasodilators in AHF trying to point out which are
\end{abstract}

\section{Metra}

Section of Cardiovascular Diseases, Department of Experimental and Applied Medicine, University of Brescia, Brescia, Italy

e-mail: metramarco@libero.it

J. R. Teerlink

Department of Cardiology, San Francisco Veterans Affairs

Medical Center and University of California,

San Francisco, CA, USA

\section{A. A. Voors}

Department of Cardiology, University Medical Center

Groningen, University of Groningen, Groningen,

The Netherlands

\section{G. M. Felker}

Division of Cardiovascular Medicine, Duke Clinical Research Institute, Durham, NC, USA

O. Milo-Cotter · B. Weatherley $\cdot$ G. Cotter $(\bowtie)$

Momentum-Research Inc., 3100 Tower Blvd,

Suite 802, Durham, NC 27707, USA

e-mail: gadcotter@momentum-research.com

H. Dittrich

University of California San Diego, San Diego,

CA, USA the potentially best indications to their administration and which are the pitfalls which may be associated with their use. Unfortunately, most of this discussion is only partially evidence based due to lack of appropriate clinical trials. In general, we believe that vasodilators should be administered early to AHF patients with normal or high blood pressure (BP) at presentation. They should not be administered to patients with low BP since they may cause hypotension and hypoperfusion of vital organs, leading to renal and/or myocardial damage which may further worsen patients' outcome. It is not clear whether vasodilators have a role in either patients with borderline BP at presentation (i.e., low-normal) or beyond the first 1-2 days from presentation. Given the limitations of the currently available clinical trial data, we cannot recommend any specific agent as first line therapy, although nitrates in different formulations are still the most widely used in clinical practice.

Keywords Acute heart failure - Vasodilators · Nitrates

\section{Introduction}

Hospitalization for AHF remains a major clinical challenge, with a high and increasing incidence, substantial morbidity and mortality, and few improvements in therapy over recent decades. Current pharmacotherapy for AHF continues to consist primarily of diuretics in almost all the patients, supplemented by vasodilators or inotropic agents in selected subsets [1]. However, the use of these agents is still based on limited evidence, generally from small, single center studies just focused on their acute hemodynamic effects. No data regarding outcomes were collected until in the recent years, and even symptoms were not thoroughly 
Table 1 Medical treatment for acute heart failure in recent European Society of Cardiology guidelines [2, 3]

In the most recent ESC guidelines [3] both nitrates and sodium nitroprusside are considered together and have a level of evidence B (*) and milrinone and enoximone have a level of evidence B $(* *)$

\begin{tabular}{llll}
\hline Group & Medication & Class of recommendation & Level of evidence \\
\hline Diuretics & Mainly loop diuretics & I & B \\
Vasodilators & Nitrates & I & B \\
& Sodium nitroprusside & I & C* \\
Morphine & Morphine & IIb & B \\
Inotropes & Dopamine & IIb & C \\
& Dobutamine & IIa & C \\
& Milrinone, enoximone & IIb & C** \\
& Levosimendan & IIa & B \\
\hline
\end{tabular}

assessed, except for the most recent drugs. Hence, as recognized in recent guidelines [2, 3], we have very limited evidence of efficacy for the agents currently used for AHF treatment (Table 1).

Second, it has become increasingly clear that AHF is not a single disease, but rather a heterogeneous family of clinical syndromes, each with a distinct clinical presentation, prognosis, and management [2, 4-7]. Data from large registries such as Acutely Decompensated Heart Failure National Registry (ADHERE) and Organized Program to Initiate Lifesaving Treatment in Hospitalized Patients with Heart Failure (OPTIMIZE) have demonstrated that a substantial portion (over three-fourths) of patients presenting with AHF have normal or elevated blood pressure (BP) at the time of presentation. Many guidelines suggest that vasodilator therapy be considered in AHF patients with high to normal $\mathrm{BP}$ on admission and avoided in those with low $\mathrm{BP}[2,3,8]$. The most recent ESC guidelines state that vasodilators "are recommended at an early stage for acute heart failure (AHF) patients without symptomatic hypotension, SBP $<90 \mathrm{mmHg}$ or serious obstructive valvular disease" [3].

Despite the high prevalence of AHF with hypertension, these recommendations are primarily based on expert opinion rather than large-scale clinical trials. Indeed, none of the currently approved intravenous vasodilators have been well studied in the subset of patients in whom they are recommended, i.e., AHF patients with elevated BP. In this review, we describe current understanding of the pathophysiology of AHF with hypertension, the rationale for vasodilator therapy in these patients, and then review the available data on approved vasodilators as well as those under investigation.

\section{Pathophysiology — why should we consider vasodilators in acute heart failure?}

Vasodilators are recommended for the early treatment of AHF associated with elevated BP at presentation. What is the underlying pathophysiology in such patients that suggest that vasodilators may be useful? Most studies suggest that vasoconstriction plays a central role in the pathogenesis of AHF via multiple mechanisms (Fig. 1). One fundamental mechanism in AHF is the interaction between a progressive decrease in cardiac performance and an acute increase in systemic vascular resistance, the so-called "afterload mismatch". This leads to a decrease in cardiac output and increase in left ventricular filling pressure. The increase in left ventricular filling pressure leads to a steep increase in pulmonary venous and hence pulmonary capillary pressure inducing exudation of fluid from the intravascular compartment into the lung interstitium and alveoli, resulting in pulmonary congestion and dyspnea.

There are multiple further mechanisms which may contribute to symptoms and the poor prognosis of patients with AHF, and they have been recently reviewed in detail [7, 9, 10]. First, as congestion increases, $\mathrm{O}_{2}$ saturation deteriorates and systemic $\mathrm{O}_{2}$ desaturation contributes to insufficient myocardial $\mathrm{O}_{2}$ supply and possibly myocardial ischemia and damage. This mechanism may be further favored by concomitant coronary artery disease, coronary vasoconstriction, caused by neurohormonal activation, and by increased myocardial oxygen demand from increased wall stress secondary to the afterload mismatch. Second, the increased fluid content in the lungs and decreased $\mathrm{O}_{2}$ saturation may induce pulmonary vasoconstriction with a further increase in $\mathrm{RV}$ pressure, again compromising left ventricular function through the ventricular interaction mechanism. Third, profound circulatory insufficiency results in metabolic acidosis, which further jeopardizes cardiac performance. Fourth, inflammatory and neurohormonal activation can lead to multiple consequences affecting cardiac and renal function as well as pulmonary membranes leading to increased "leak" of fluid into alveoli, further amplifying congestion. Finally, decreased forward perfusion, increased venous pressure, and neurohormonal-inflammatory activation lead to further impairment in renal function that in turn worsens heart failure.

As noted above, large registries such as ADHERE and OPTIMIZE demonstrate that most patients with AHF have either preserved or increased $\mathrm{BP}$ at presentation $[5,11]$. These registries may actually underestimate the importance 
Fig. 1 The central role of vasoconstriction in the pathogenesis of acute heart failure. (modified from:

Teerlink JR, O'Connor CM. Endothelin receptor antagonists in the treatment of acute heart failure. In CM O'Connor, WG Stough, M Gheorghiade, KF Adams (editors): Managing Acute Decompensated Heart Failure: A Clinician's Guide for Diagnosis and Treatment. London, Taylor and Francis, LTD, 2005)

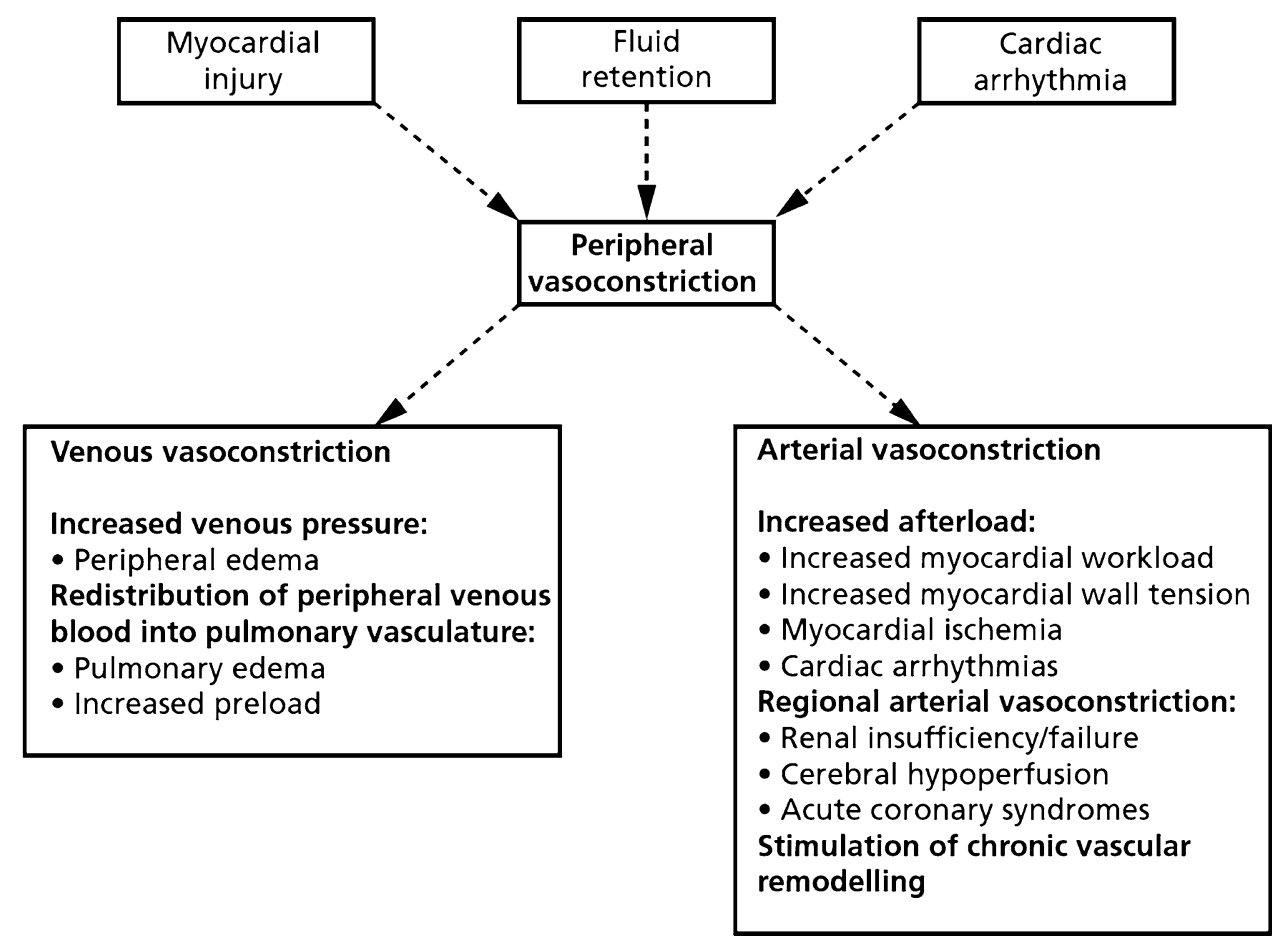

of hypertension, because the first BP recorded was usually a few hours after presentation and sometimes after initial treatment was administered. In a recent comprehensive small study that captured the initial BP in the emergency department or in the ambulance in all the patients admitted with AHF to a community hospital, the vast majority of patients were hypertensive at admission with only about $10 \%$ of patients having "normal" or low BP at presentation [12]. In a hemodynamic study where data were collected in patients admitted to the hospital with an AHF event, the most notable change in hemodynamic measures leading to heart failure was a very steep increase in vascular resistance and BP [13]. Patients admitted for AHF with high BP are more likely to be females, elderly, with a history of hypertension, and with a normal left ventricular ejection fraction $[14,15]$.

Taken as a whole, these data suggest that changes in vascular tone, possibly both on the arterial side (increasing afterload) and venous side (increasing pre-load), are important contributors to $\mathrm{AHF}$ and may be a crucial determinant of the AHF syndrome in patients with AHF and elevated BP (recently termed acute vascular or cardiovascular AHF).

\section{Potential risks and benefits of vasodilators in AHF}

Treatment goals in AHF should be aligned with the general principles of drug therapy-i.e., that interventions in any disease should make patients "feel better" and/or "live longer". Vasodilators in AHF were traditionally developed to make patients "feel better", which in AHF has typically been assessed as the early and sustained relief of dyspnea. As with all symptoms relief, however, it is crucial that such improvement is not achieved at the expense of greater "downstream" risks for outcomes such as endorgan damage, hospitalization, or death. Avoidance of hypotension and end-organ hypoperfusion seems to play a crucial role.

Despite their long history of use, the body of evidence to understand the safety profile of vasodilators in AHF remains limited. Retrospective analyses of pooled data for nesiritide suggested the possibility of worsening renal function and increased mortality, leading to substantial controversy about the safety of this agent $[16,17]$. Of note, in the studies that were used for this meta-analysis, patients with systolic BPs $<90 \mathrm{mmHg}$ were allowed. In patients with low systolic BP, renal perfusion might be seriously jeopardized when a vasodilator is added, leading to increased risks of worsening renal function. In other groups of patients with systolic dysfunction, nesiritide treatment was not associated with worsening renal function nor was even related to improvement of renal dysfunction [18, 19].

Further concerns are related to the effects of vasodilators on coronary perfusion and myocardial damage. Studies based on serial measurements of serum troponin levels have shown that a consistent proportion of AHF patients, also including patients with idiopathic dilated cardiomyopathy, develop myocardial damage at the time of their admission. In a study by Metra et al., detectable serum 
troponin $\mathrm{T}$ levels were found in $48 \%$ of the patients admitted for AHF (54\% of the patients with coronary artery disease and $40 \%$ of those with idiopathic dilated cardiomyopathy) [20]. Excessive hypotension may lead to coronary hypoperfusion and cause myocardial damage. Further, although this is not the case for nitrates, vasodilators may preferentially dilate normal coronary vessels causing "coronary steal" with further decline of blood flow in diseased vessels.

The results of one of the earliest randomized, placebocontrolled, double-blind trials of vasodilators in patients with left ventricular dysfunction were actually consistent with the hypothesis that vasodilators may be detrimental in patients with ongoing myocardial ischemia. In this trial, Cohn et al. randomized 812 men with presumed acute myocardial infarction and left ventricular filling pressure $\geq 12 \mathrm{mmHg}$ to a placebo or sodium nitroprusside $48 \mathrm{~h}$ infusion. Results on mortality were strongly affected by the time of treatment with a deleterious effect of sodium nitroprusside when infusion was started at $<9 \mathrm{~h}$ from the onset of symptoms (mortality at 13 weeks, $24.2 \%$ vs. $12.7 \% ; P=0.025)$ and a beneficial effect in those whose infusion was begun later (mortality at 13 weeks, $14.4 \%$ vs. $22.3 \% ; P=0.04)$ [21]. These results are consistent with the hypothesis that vasodilator therapy may aggravate coronary hypoperfusion and, when associated with hypotension, may be deleterious in the setting of myocardial ischemia. They, however, also show that vasodilator treatment may favorably affect outcomes when used appropriately in patients with cardiac dysfunction.

More recent data also indicate that excessive peripheral vasodilatation may be deleterious in patients with AHF. A retrospective analysis of data from the Evaluation Study of Congestive Heart Failure and Pulmonary Artery Catheterization Effectiveness (ESCAPE) has shown that the combination of intravenous vasodilators and inotropes is associated with a risk-adjusted increased mortality which is even higher (hazard ratio, HR, 4.81, 95\% confidence intervals, CI, 2.34-9.90) than with inotropes alone (HR, 2.14, 95\% CI 1.10-4.15). Vasodilators alone, however, were not associated with a significant increase in the risk of death (HR, 1.39, 95\% CI 0.64-3.00). Similar data were found when the combined end-point of death plus rehospitalizations were considered [22]. Consistently, the lack of improvement in outcomes with levosimendan, compared to dobutamine, in SURVIVE has been ascribed also to the vasodilatatory effects and hypotension associated with levosimendan administration as observed in this trial [23].

Thus, we are left with doubts regarding the effects of vasodilators on outcomes, and even symptoms, in the patients with AHF. No single study of vasodilators in AHF has been sufficiently powered to carefully evaluate safety, and in particular, no adequately powered prospective studies have been performed with nitrates or sodium nitroprusside, the most commonly used vasodilators in AHF. Do vasodilators as a class lead to worsening renal function, end-organ damage, or increase the rate of post-discharge re-admission and death in AHF? Although currently available data do not permit a definitive answer to this question, we believe that the answer is no. First, we believe that safety of vasodilator therapy can be significantly increased by focusing on those patients most likely to benefit: patients with AHF and normal or elevated BP. In addition, careful monitoring of BP during treatment and down titration or discontinuation of vasodilator therapy, if BP drops significantly, may improve the safety profile of these agents. Finally, these agents may have U-shaped dose-effect relationships. While it is widely recognized that sub-optimal doses of vasodilators may have a limited effect, administration of high doses might also reduce their effectiveness because of counter regulatory mechanisms. In some cases, vasodilators doses were chosen based on small hemodynamic studies largely confined to patients with stable severe chronic heart failure with systolic dysfunction. The doses chosen were those achieving the maximal possible vasodilatation, or largest increase in cardiac index and decrease in pulmonary wedge pressure (PWP). However, in patients with AHF in whom cardiac reserve is reduced, inappropriate vasodilatation may induce a steep reduction in $\mathrm{BP}$, resulting in hemodynamic instability, ischemia, renal failure, and sometimes frank shock. In addition, high-dose vasodilators can induce rebound neurohormonal activation potentially limiting short- and longterm efficacy [24-26]. Therefore, the administration of these drugs should be done with caution, to the patients who really deserve them, using the right doses, under careful BP monitoring, and with careful titration of the dose according to changes in BP. Large, carefully controlled prospective studies will be required to provide conclusive evidence of the safety and efficacy of vasodilator therapy in AHF.

\section{Choice of vasodilator in AHF: currently available therapies}

\section{Nitrovasodilators}

Nitrates, which have been used as vasodilators in AHF for many years, have never been evaluated in a prospective randomized study. In small studies, nitrates have been shown to improve some aspects of the AHF syndrome. In the VMAC study, fixed low doses of nitrates were shown to improve some aspects of dyspnea during the first hours of administration [27]. However, no prospective randomized study has examined the use of higher doses, above all with the option of careful dose titration according to BP changes, on any component of the clinical syndrome of AHF. 
Cotter et al. have shown that high-dose early administration of intravenous nitrates is beneficial in improving arterial oxygenation or potentially preventing some consequences of AHF (myocardial infarction [MI], need for mechanical ventilation), compared to furosemide alone [28] or noninvasive ventilation [29], respectively, although these studies were small and not blinded. The effects of nitrates on end-organ damage (renal impairment, MI, cardiac arrest) or on intermediate and long term outcomes (readmission and death) were never examined. Importantly, the use of continuous intravenous administration of nitrates beyond a few hours is associated with tolerance, and to maintain efficacy, nitrates need to be continuously uptitrated against BP [30].

Sodium nitroprusside is an intravenous vasodilator commonly used in the past in patients with refractory heart failure. It is administered almost exclusively in critical care settings, sometimes with careful invasive hemodynamic monitoring to avoid the risk of inducing hypotension. Accurate non-invasive BP monitoring is also a reasonable alternative to invasive measurements. Prolonged use of nitroprusside has been rarely associated with the risk of thiocyanate toxicity. Neurohormonal activation and rebound vasoconstriction after its abrupt withdrawal have been described [24, 31]. These concerns have hindered the general enthusiasm in using nitroprusside in the contemporary management of AHF, even though its favorable hemodynamic effects have been well documented. A recent analysis by Mullens et al. of 175 consecutive patients admitted for acutely decompensated heart failure, showed that intravenous sodium nitroprusside, although administered to the patients with a worse hemodynamic profile at baseline, was associated with greater hemodynamic improvement and lower rates of inotropic support or worsening renal function during hospitalization and with lower rates of all-cause mortality after discharge [32].

\section{Nesiritide}

Nesiritide is the only vasodilator recently approved for the treatment of AHF. Approval, however, accorded by the US Food and Drug Administration and not by European regulatory agencies [2, 3, 8]. Early studies demonstrated favorable effects on hemodynamics, including reductions in PWP and systemic vascular resistance which were accompanied by an increase in cardiac output [33, 34]. These results were confirmed by the Vasodilatation in the Management of Acute Congestive Heart Failure (VMAC) study that showed some beneficial effects of nesiritide on dyspnea in patients admitted for AHF, half of whom were monitored by pulmonary artery catheters. Dyspnea improvement was demonstrated at $3 \mathrm{~h}$ compared to the placebo group [27]. However, besides this short-term improvement in dyspnea, other effects of nesiritide, such as persistence of the dyspnea improvement, potential harmful effects on end organs or increased re-admission and death, have not been studied prospectively in a large number of patients. Moreover, additional data analysis raised concerns regarding its safety, with respect to its effects on kidney function and short-term mortality [16, 17]. Currently, the on-going Acute Study of Clinical Effectiveness of Nesiritide in Subjects with Decompensated Heart Failure (ASCEND-HF) study is addressing these issues in 7,000 patients admitted with AHF and randomized to nesiritide or placebo.

\section{Choice of vasodilator in AHF: investigational therapies}

Endothelin antagonists

Endothelin (ET)-1 is a powerful vasoconstrictor that is used increasingly in heart failure and when higher ET-1 levels are observed in patients with more symptomatic heart failure [35-37]. Furthermore, ET-1 was shown to correlate with the outcome of patients admitted for decompensated AHF [38]. On the basis of these pathophysiological data, several endothelin antagonists were developed for potential cardiovascular use, including darusentan, sitaxsentan, bosentan, and tezosentan.

Tezosentan is an intravenous dual $\left(\mathrm{ET}_{\mathrm{A}}\right.$ and $\left.\mathrm{ET}_{\mathrm{B}}\right)$ receptor-competitive antagonist of endothelin-1 (ET-1) that was extensively studied in AHF. It is associated with vasodilatory effects that result in increased cardiac index and reduced PWP. The hemodynamic and clinical effects of tezosentan were evaluated in a series of large double-blind, parallel-group, phase III studies, collectively known as the RITZ (Randomized Intervention of TeZosentan) program. Even though safety trials showed that tezosentan was relatively safe in high-risk patients with AHFS associated with acute coronary syndromes or with acute cardiogenic pulmonary edema, the results of the RITZ program did not demonstrate a clinical benefit as there was no reduction in the rate of recurrent heart failure events in the tezosentantreated patients despite significant hemodynamic effects [39-42]. The Value of Endothelin Receptor Inhibition with Tezosentan in Acute Heart Failure Study (VERITAS) [43, 44] was a large-scale international trial designed to study the effects of tezosentan added to conventional therapy in patients with AHF hospitalized for dyspnea, on dyspnea relief and worsening HF events. The trial was discontinued because of the low probability of achieving a significant treatment effect, after a recommendation based on prespecified rules by the Data Safety and Monitoring Board. Hence, there is no clear evidence to support administration of endothelin antagonists in AHF. 
Other natriuretic peptides

\section{Ularitide}

Ularitide is a synthetic analogue of urodilatin, a member of the family of atrial or A-type natriuretic peptides (ANP) produced locally in the renal tubular cells which plays an important role in sodium and water excretion [45]. Early studies in patients with HF reported favorable hemodynamic effects and possibly enhanced diuresis and natriuresis with ularitide. SIRIUS I (24 patients) [46] and SIRIUS II (221 patients) [47, 48] studied three doses of ularitide compared to placebo among patient hospitalized with AHF. Ularitide was found to have beneficial symptomatic, hemodynamic (PWP and cardiac index), and neurohormonal effects. The most frequent adverse event was hypotension, reported in up to $5 \%$ in active groups. Ularitide has not been studied in a large prospective randomized study examining either symptoms improvement or outcome of patients with AHF.

\section{$C D-N P$}

$\mathrm{CD}-\mathrm{NP}$ is a chimeric natriuretic peptide - a fusion peptide of the full-length 22-AA structure of c-type natriuretic peptide (CNP) together with the 15-AA C-terminus of d-type natriuretic peptide (DNP). In animal models, CD-NP was shown to have natriuretic and diuretic, glomerular filtration rate (GFR)-enhancing, renin inhibiting and unloading effects, with less hypotensive properties when compared to BNP. In addition, CD-NP in vitro possesses cGMP activating and anti-proliferative properties in cultured fibroblasts. Preliminary data suggest that the drug is a more selective venovasodilator and diuretic/natriuretic agent. This drug is being evaluated in phase II human studies in patients with heart failure and AHF [49].

\section{Relaxin}

Relaxin is a peptide made up of 53 amino acids which shares structural (although not functional) similarities with insulin including its production as a single-chain molecule that folds and undergoes removal of a C-peptide to yield a 2-chain molecule with conserved disulfide bonds. Relaxin's activity is initiated by binding to its cognate receptor, LGR7, which is present in the renal and systemic vasculature [50]. Importantly, relaxin has multiple mechanisms of action including effects on nitric oxide (NO) [51], the endothelin type $B$ receptor [52], atrial natriuretic peptide [53], and vascular endothelial growth factor in the endometrium [54]. Relaxin also activates matrix metalloproteinases (MMPs) that may lead to increase in arterial compliance. In a single site, open-label study of relaxin in patients with compensated heart failure intravenous relaxin given for $24 \mathrm{~h}$ was associated with decreases from baseline in PWP and systemic vascular resistance, and increases in cardiac index, all of which achieved statistical significance at certain time points, although the PWP decreases were observed at lower doses than the increases in cardiac output. No consistent changes in heart rate or BP were observed either during or post-dosing. The early administration of relaxin is currently being tested in a phase II/III program (RELAX-AHF) in patients with AHF and high BP at the time of admission.

BAY 58-2667-NO and heme-independent soluble G protein activator

A major pathway of vascular tone control is mediated by NO. Binding of NO to the ferrous heme iron of soluble guanylate cyclase (sGC) activates the enzyme and leads to conversion of GTP to cGMP, which leads to vasodilatation. BAY 58-2667 activates sGC not only independently of NO but also independently of the prosthetic heme group. In a model of tachycardia pacing-induced severe heart failure, BAY 58-2667 caused a dose-dependent reduction in BP, right atrial, pulmonary artery pressure, and PWP an increase in cardiac output and renal blood flow, with no change in glomerular filtration rate, urine flow and urine sodium excretion [55]. Similar effects were observed in a small proof of concept study in patients with acute decompensated heart failure [56]. Phase II and III studies with this compound in AHF are planned. Theoretically, BAY 58-2667 may induce predictable and easily reversible effects on vascular tone that are endothelium independent, and hence reproducible, even in patients with severe endothelial dysfunction.

\section{Adenosine blockers—-selective renal vasodilatation}

Administration of loop diuretics to patients with AHF is attended by a decrease in renal blood flow and glomerular filtration rate. This response (the so-called tubuloglomerular mechanism) is mediated by adenosine release caused by the activation of the juxtaglomerular apparatus cells which sense the furosemide-associated increased sodium loading at the level of the distal tubule. Adenosine release causes a decrease in renal blood flow and GFR through constriction of the afferent glomerular arteriole mediated by type-1A adenosine receptors. Early studies have shown that the co-administration of adenosine type-1A receptor antagonists may blunt the decrease in GFR associated with furosemide administration in patients with heart failure [57]. Seminal work by Dittrich et al. showed that the administration of the selective adenosine $\mathrm{A}_{1}$ blocker, rolofylline significantly increases both renal blood flow and glomerular filtration rate in patients with heart failure [58]. 
Consistent with these findings, further clinical studies showed that the administration of type $1 \mathrm{~A}$ adenosine antagonists increases diuresis and natriuresis with a concomitant preservation of renal function in patients with acutely decompensated heart failure and fluid overload [59]. In the PROTECT pilot study Cotter \& Dittrich et al. have shown that the administration of the $A_{1}$ receptor antagonist, rolofylline, to patients with AHF may induce improvement in dyspnea and have reno-protective effects that translated into trends in reduced rates of re-admission and death up to 2 months from treatment [60]. These potential beneficial effects are examined in a series of phase II and III studies in which the safety and efficacy of the above mentioned drugs are examined in detail.

\section{Conclusions}

Vasodilators may be beneficial in patients with AHF. However, this has never been shown in a prospective wellpowered and conducted study. Some newer and older drugs are being tested and the results of these studies should enable us to finally answer some important clinical questions, including the following:

(a) Do vasodilators make patients "feel better"?

(b) Is this effect clinically significant (i.e., appears early, is sustained, and potentially leads to shorter length of hospital stay)?

(c) Can these effects be achieved without collateral damage to vital organs such as the kidney, heart and brain-or even while improving these organ functions?

(d) Can this be achieved without leading to detrimental effects on re-admission or death or even reduce these outcomes?

(e) Which patients should be treated and for how long?

(f) Are all vasodilators equal or are veno vasodilators or renal vasodilators superior?

Open Access This article is distributed under the terms of the Creative Commons Attribution Noncommercial License which permits any noncommercial use, distribution, and reproduction in any medium, provided the original author(s) and source are credited.

\section{References}

1. Constanzo MR, Johannes RS, Pine M et al (2007) The safety of intravenous diuretics alone versus diuretics plus parenteral vasoactive therapies in hospitalized patients with acutely decompensated heart failure: a propensity score and instrumental variable analysis using the Acutely Decompensated Heart Failure National Registry (ADHERE) database. Am Heart J 154:267277. doi:10.1016/j.ahj.2007.04.033
2. Nieminen MS, Bohm M, Cowie MR et al (2005) Executive summary of the guidelines on the diagnosis and treatment of acute heart failure: the Task Force on Acute Heart Failure of the European Society of Cardiology. Eur Heart J 26:384-416. doi: 10.1093/eurheartj/ehi044

3. Dickstein K, Cohen-Solal A, Filippatos G et al (2008) ESC guidelines for the diagnosis and treatment of acute and chronic heart failure 2008: the Task Force for the diagnosis and treatment of acute and chronic heart failure 2008 of the European Society of Cardiology. Developed in collaboration with the Heart Failure Association of the ESC (HFA) and endorsed by the European Society of Intensive Care Medicine (ESICM). Eur J Heart Fail 10:933-989

4. Gheorghiade M, Zannad F, Sopko G et al (2005) Acute heart failure syndromes: current state and framework for future research. Circulation 112:3958-3968. doi:10.1161/CIRCULATIONAHA. 105.590091

5. Gheorghiade M, Abraham W, Albert N et al (2006) Systolic blood pressure at admission, clinical characteristics, and outcomes in patients hospitalized with acute heart failure. J Am Med Assoc 296:2217-2226. doi:10.1001/jama.296.18.2217

6. Filippatos G, Zannad F (2007) An introduction to acute heart failure syndromes: definition and classification. Heart Fail Rev 12:87-90. doi:10.1007/s10741-007-9008-3

7. Teerlink JR (2008) Diagnosis and management of acute heart failure. In: Libby P, Bonow RO, Mann DL, Zipes DP (eds) Braunwald's heart disease, vol 8. Philadelphia, Elsevier, pp 583-610

8. Heart Failure Society of America (2006) Executive summary: HFSA 2006 comprehensive heart failure practice guideline. J Card Fail 12:10-38. doi:10.1016/j.cardfail.2005.12.001

9. Cotter G, Metra M, Milo-Cotter O, Dittrich HC, Gheorghiade M (2008) Fluid overload in acute heart failure-re-distribution and other mechanisms beyond fluid accumulation. Eur J Heart Fail 10:165-169. doi:10.1016/j.ejheart.2008.01.007

10. Cotter G, Felker GM, Adams KF, Milo-Cotter O, O'Connor CM (2008) The pathophysiology of acute heart failure-is it all about fluid accumulation? Am Heart J 155:9-18. doi:10.1016/j.ahj. 2006.02.038

11. Adams KF Jr, Fonarow GC, Emerman CL et al (2005) ADHERE Scientific Advisory Committee and Investigators Characteristics and outcomes of patients hospitalized for heart failure in the United States: rationale, design, and preliminary observations from the first 100, 000 cases in the Acute Decompensated Heart Failure National Registry (ADHERE). Am Heart J 149:209-216. doi:10.1016/j.ahj.2004.08.005

12. Milo-Cotter O, Adams KF, O'Connor CM, Uriel N, Felker GM, Weatherley B, Vered Z, Cotter G (2007) Acute heart failure associated with high admission blood pressure-a distinct vascular disorder? Eur J Heart Fail 9:178-183. doi:10.1016/j. ejheart.2006.06.004

13. Cotter G, Moshkovitz Y, Kaluski E, Milo O, Nobikov Y, Schneeweiss A, Krakover R, Vered Z (2003) The role of cardiac power and systemic vascular resistance in the pathophysiology and diagnosis of patients with acute congestive heart failure. Eur J Heart Fail 5:443-451. doi:10.1016/S1388-9842(03)00100-4

14. Gandhi SK, Powers JC, Nomier AM et al (2001) The pathogenesis of acute pulmonary edema associated with hypertension. N Engl J Med 344:17-22. doi:10.1056/NEJM20010104 3440103

15. Lenzen MJ, Scholte op Reimer WJ, Boersma E, Vantrimpont PJ, Follath F, Swedberg K, Cleland J, Komajda M (2004) Differences between patients with a preserved and a depressed left ventricular function: a report from the EuroHeart Failure Survey. Eur Heart J 25:1214-1220. doi:10.1016/j.ehj.2004.06.006

16. Sackner-Bernstein JD, Skopicki HA, Aaronson KD (2005) Risk of worsening renal function with nesiritide in patients with 
acutely decompensated heart failure. Circulation 111:1487-1491. doi:10.1161/01.CIR.0000159340.93220.E4

17. Sackner-Bernstein JD, Kowalski M, Fox M, Aaronson K (2005) Short-term risk of death after treatment with nesiritide for decompensated heart failure: a pooled analysis of randomized controlled trials. J Am Med Assoc 293:1900-1905. doi: 10.1001/jama.293.15.1900

18. Yancy CW, Saltzberg MT, Berkowitz RL et al (2004) Safety and feasibility of using serial infusions of nesiritide for heart failure in an outpatient setting (from the FUSION I trial). Am J Cardiol 94:595-601. doi:10.1016/j.amjcard.2004.05.022

19. Mentzer RM Jr, Oz MC, Sladen RN, Graeve AH, Hebeler RF Jr, Luber JM Jr, Smedira NG, NAPA Investigators (2007) Effects of perioperative nesiritide in patients with left ventricular dysfunction undergoing cardiac surgery: the NAPA Trial. J Am Coll Cardiol 49:716-726. doi:10.1016/j.jacc.2006.10.048

20. Metra M, Nodari S, Parrinello G et al (2007) The role of plasma biomarkers in acute heart failure. Serial changes and independent prognostic value of NT-proBNP and cardiac troponin-T. Eur J Heart Fail 9:776-786. doi:10.1016/j.ejheart.2007.05.007

21. Cohn JN, Franciosa JA, Francis GS et al (1982) Effect of shortterm infusion of sodium nitroprusside on mortality rate in acute myocardial infarction complicated by left ventricular failure: results of a Veterans Administration cooperative study. N Engl J Med 306:1129-1135

22. Elkayam U, Tasissa G, Binanay C et al (2007) Use and impact of inotropes and vasodilator therapy in hospitalized patients with severe heart failure. Am Heart J 153:98-104. doi:10.1016/j.ahj. 2006.09.005

23. Mebazaa A, Nieminen MS, Packer M et al (2007) Levosimendan vs dobutamine for patients with acute decompensated heart failure: the SURVIVE Randomized Trial. J Am Med Assoc 297:1883-1891. doi:10.1001/jama.297.17.1883

24. Francis GS, Olivari MT, Goldsmith SR, Levine TB, Pierpont G, Cohn JN (1983) The acute response of plasma norepinephrine, renin activity, and arginine vasopressin to short-term nitroprusside and nitroprusside withdrawal in patients with congestive heart failure. Am Heart J 106:1315-1320. doi:10.1016/00028703(83)90039-X

25. Troughton RW, Lewis LK, Yandle TG, Richards AM, Nicholls MG (2000) Hemodynamic, hormone, and urinary effects of adrenomedullin infusion in essential hypertension. Hypertension 36:588-593

26. Giles TD, Pina IL, Quiroz AC et al (1992) Hemodynamic and neurohormonal responses to intravenous Nicorandil in congestive heart failure in humans. J Cardiovasc Pharmacol 20:572-578. doi:10.1097/00005344-199210000-00010

27. Publication Committee for the VMAC [Vasodilatation in the Management of Acute CHF] Investigators (2002) Intravenous nesiritide vs. nitroglycerin for treatment of decompensated congestive heart failure: a randomized controlled trial. JAMA 287:1531-1540

28. Cotter G, Metzkor E, Kaluski E et al (1998) Randomised trial of high-dose isosorbide dinitrate plus low-dose furosemide versus high-dose furosemide plus low-dose isosorbide dinitrate in severe pulmonary oedema. Lancet 351:389-393. doi:10.1016/S01406736(97)08417-1

29. Sharon A, Shpirer I, Kaluski E et al (2000) High-dose intravenous isosorbide-dinitrate is safer and better than Bi-PAP ventilation combined with conventional treatment for severe pulmonary edema. J Am Coll Cardiol 36:832-837. doi:10.1016/S0735-1097 (00)00785-3

30. Elkayam U, Bitar F, Akhter MW, Khan S, Patrus S, Derakhshani M (2004) Intravenous nitroglycerin in the treatment of decompensated heart failure: potential benefits and limitations.
J Cardiovasc Pharm Ther 9:227-241. doi:10.1177/107424840 400900403

31. Packer M, Meller J, Medina N, Gorlin R, Herman MV (1979) Rebound hemodynamic events after the abrupt withdrawal of nitroprusside in patients with severe chronic heart failure. N Engl J Med 301:1193-1197

32. Mullens W, Abrahams Z, Francis GS, Skouri HN, Starling RC, Young JB, Taylor DO, Tang WH (2008) Sodium nitroprusside for advanced low-output heart failure. J Am Coll Cardiol 52:200 207. doi:10.1016/j.jacc.2008.02.083

33. Colucci WS, Elkayam U, Horton DP et al (2000) Intravenous nesiritide, a natriuretic peptide, in the treatment of decompensated congestive heart failure. N Engl J Med 343:246-253. doi: 10.1056/NEJM200007273430403

34. Mills RM, LeJemtel TH, Horton DP et al (1999) Sustained hemodynamic effects of an infusion of nesiritide (human b-type natriuretic peptide) in heart failure: a randomized, double-blind, placebo-controlled clinical trial. J Am Coll Cardiol 34:155-162. doi:10.1016/S0735-1097(99)00184-9

35. Yanagisawa M, Kurihara H, Kimura Y et al (1988) A novel potent vasoconstrictor peptide produced by vascular endothelial cells. Nature 332:411-415. doi:10.1038/332411a0

36. Teerlink JR (2002) The role of endothelin in the pathogenesis of heart failure. Curr Cardiol Rep 4:206-212. doi:10.1007/s11886002-0052-2

37. Love MP, McMurray JJV (1996) Endothelin in chronic heart failure: current position and future prospects. Cardiovasc Res 31:665-674

38. Aronson D, Burger AJ (2003) Neurohormonal prediction of mortality following admission for decompensated heart failure. Am J Cardiol 91:245-248. doi:10.1016/S0002-9149(02)03119-3

39. Teerlink JR, Massie BM, Cleland JGF, Tzivoni D, for the RITZ-1 Investigators (2001) A double-blind, parallel-group, multi-center, placebocontrolled study to investigate the efficacy and safety of tezosentan in reducing symptoms in patients with acute decompensated heart failure. Circulation 104:II-526. abstract

40. Torre-Amione G, Young JB, Colucci WS et al (2003) Hemodynamic and clinical effects of tezosentan, an intravenous dual endothelin receptor antagonist, in patients hospitalized for acute decompensated heart failure. J Am Coll Cardiol 42:140-147. doi: 10.1016/S0735-1097(03)00556-4

41. O'Connor CM, Gattis WA, Adams KF Jr et al (2003) Tezosentan in patients with acute heart failure and acute coronary syndromes: results of the Randomized Intravenous TeZosentan Study (RITZ-4). J Am Coll Cardiol 41:1452-1457. doi:10.1016/S07351097(03)00194-3

42. Kaluski E, Kobrin I, Zimlichman R et al (2003) RITZ-5: randomized intravenous TeZosentan (an endothelin-A/B antagonist) for the treatment of pulmonary edema: a prospective, multicenter, doubleblind, placebo-controlled study. J Am Coll Cardiol 41:204-210. doi:10.1016/S0735-1097(02)02708-0

43. Teerlink JR, McMurray JJ, Bourge RC et al (2005) Tezosentan in patients with acute heart failure: design of the Value of Endothelin Receptor Inhibition with Tezosentan in Acute heart failure Study (VERITAS). Am Heart J 150:46-53. doi:10.1016/j.ahj. 2005.04.035

44. McMurray JJ, Teerlink JR, Cotter G et al (2007) Effects of tezosentan on symptoms and clinical outcomes in patients with acute heart failure: the VERITAS randomized controlled trials. J Am Med Assoc 298:2009-2019. doi:10.1001/jama.298.17.2009

45. Forssmann W, Meyer M, Forssmann K (2001) The renal urodilatin system: clinical implications. Cardiovasc Res 51:450-462. doi:10.1016/S0008-6363(01)00331-5

46. Mitrovic V, Luss H, Nitsche $\mathrm{K}$ et al (2005) Effects of the renal natriuretic peptide urodilatin (ularitide) in patients with 
decompensated chronic heart failure: a double-blind, placebocontrolled, ascending-dose trial. Am Heart J 150:1239.e1-8

47. Mitrovic V, Seferovic PM, Simeunovic D et al (2006) Haemodynamic and clinical effects of ularitide in decompensated heart failure. Eur Heart J 27:2823-2832. doi:10.1093/eurheartj/ehl337

48. Lüss H, Mitrovic V, Seferovic PM et al (2008) Renal effects of ularitide in patients with decompensated heart failure. Am Heart $\mathrm{J}$ 155:1012.e1-8

49. Lisy O, Huntley BK, McCormick DJ, Kurlansky PA, Burnett JC Jr (2008) Design, synthesis, and actions of a novel chimeric natriuretic peptide: CD-NP. J Am Coll Cardiol 52:60-68. doi: 10.1016/j.jacc.2008.02.077

50. Novak J, Parry LJ, Matthews JE et al (2006) Evidence for local relaxin ligand-receptor expression and function in arteries. FASEB J 20:2352-2362. doi:10.1096/fj.06-6263com

51. Bani-Sacchi T, Bigazzi M, Bani D, Mannaioni PF, Masini E (1995) Relaxin-induced increased coronary flow through stimulation of nitric oxide production. Br J Pharmacol 116:1589-1594

52. Danielson LA, Sherwood OD, Conrad KP (1999) Relaxin is a potent renal vasodilator in conscious rats. J Clin Invest 103:525533. doi:10.1172/JCI5630

53. Toth M, Taskinen P, Ruskoaho H (1996) Relaxin stimulates atrial natriuretic peptide secretion in perfused rat heart. J Endocrinol 150:487-495. doi:10.1677/joe.0.1500487

54. Unemori EN, Erikson ME, Rocco SE, Sutherland KM, Parsell DA, Mak J, Grove BH (1999) Relaxin stimulates expression of vascular endothelial growth factor in normal human endometrial cells in vitro and is associated with menometrorrhagia in women. Human Reprod (Oxford, England) 14:800-806. doi:10.1093/ humrep/14.3.800
55. Boerrigter G, Costello-Boerrigter LC, Cataliotti A, Lapp H, Stasch JP, Burnett JC Jr (2007) Targeting heme-oxidized soluble guanylate cyclase in experimental heart failure. Hypertension 49:1128-1133. doi:10.1161/HYPERTENSIONAHA.106.083832

56. Mitrovic V, Lapp H, Franz N et al (2008) The soluble guanilate cyclase activator BAY 58-2667 has a favourable safety profile and improbe cardiopulmonary hemodynamics in acute decompensated heart failure. Eur J Heart Fail 7(Suppl 1):1. abstract

57. Gottlieb SS, Brater DC, Thomas I et al (2002) BG9719 (CVT124), an $A_{1}$ adenosine receptor antagonist, protects against the decline in renal function observed with diuretic therapy. Circulation 105:1348-1353. doi: $10.1161 / \mathrm{hc} 1102.105264$

58. Dittrich HC, Gupta DK, Hack TC, Dowling T, Callahan J, Thomson S (2007) The effect of KW-3902, an adenosine $A_{1}$ receptor antagonist, on renal function and renal plasma flow in ambulatory patients with heart failure and renal impairment. J Card Fail 13:609-617. doi:10.1016/j.cardfail.2007.08.006

59. Givertz MM, Massie BM, Fields TK, Pearson LL, Dittrich HC, CKI-201, CKI-202 Investigators (2007) The effects of KW-3902, an adenosine $\mathrm{A}_{1}$-receptor antagonist, on diuresis and renal function in patients with acute decompensated heart failure and renal impairment or diuretic resistance. J Am Coll Cardiol 50:1551-1560. doi:10.1016/j.jacc.2007.07.019

60. Cotter G, Dittrich HC, Davison Weatherley B, Bloomfield DM, O'Connor CM, Metra M, Massie BM, Protect Steering Committee, Investigators and Coordinators (2008) The PROTECT pilot study: a randomized, placebo-controlled, dose-finding study of the adenosine $\mathrm{A}(1)$ receptor antagonist rolofylline in patients with acute heart failure and renal impairment. J Card Fail 14:631-640. doi:10.1016/j.cardfail.2008.08.010 